\title{
Worlds turned back to front: the politics of the mirror universe in Doctor Who and Star Trek
}

It is a curious parallel that unquestionably the most successful science fiction television series to emerge from the UK and the US both began in the 1960s, endured lengthy hiatuses, oscillated between mainstream and cult appreciation, and both currently revel in their crossmedia commercial appeal. Doctor Who (1963-89, 2005-present) and Star Trek (1966-9), through their lengthy broadcast histories, might be used to chart any number of cultural shifts in their host communities. Far from being abstruse and introspective creations of geeky fandoms, both have been central to the popular culture of their respective societies - Matt Hills noted that 'for much of its cultural life Doctor Who has actually occupied the mainstream of British television programming' (Hills 2010: 98); John Tulloch's and Henry Jenkins' examination of science fiction audiences make it clear that in creating Star Trek Gene Roddenberry evinced a 'desire to reach a mass viewership and a desire to address the burning social issues of the day' (Jenkins and Tulloch 1995: 7). Popular television in general has always been a prime site for the exploration of pressing social concerns (Williams 1974: 58), and science fiction is also often politically engaged: Hassler and Wilcox point out that '[p]olitical science often addresses many of the same questions as those raised in science fiction...the role of the state...the nature of the just society' (Hassler and Wilcox 1997: 1). Doctor Who and Star Trek are both notable for openly or covertly addressing the distinctive social and political problems faced by their respective societies. Star Trek returned to the question of the Vietnam War's legitimacy multiple times (Franklin 2000: 131-50), 'and other episodes were commentaries on race relations, feminism, and the hippies of the 1960s' (Reagin 2013: 2). Under Russell T. Davies' revival Doctor Who continually referenced the 'war on terror' (Charles 2008), but the 'classic' serial also engaged with contemporary British politics: the Sylvester McCoy series were openly anti-Thatcherite (O’Day 2010: 271-8), while in the 1970s under producer Barry Letts many Doctor Who serials dealt with environmental issues and their politics (Orthia 2011: 26-30). The disparate political engagements present in Doctor Who are generally anti-authoritarian, and the Doctor "has consistently ... [the] liberal-populist role in criticising "sectionalist" forces of "Left" and "Right", and in rebuking the "official" and the powerful' (Tulloch and Alvarado 1983: 52). This pragmatic politics, however, was not available to Star Trek, which 'was created as a style of social commentary, intent on criticising America in the late 1960s during a period of extreme social and political turmoil', and therefore wrestling with the contradictions between the philosophical absolutes of American exceptionalism and 'manifest destiny' (Geraghty 2007: 72).

By 1970 Star Trek had been off-air in the United States for three years, but was in its first run on British television, and thus competing directly with Doctor Who for the telefantasy audience. First broadcast in the UK simultaneously in 1970, the Doctor Who seven-part adventure 'Inferno' (1970) and the Star Trek episode 'Mirror, Mirror' (1967) use the same basic plot devices - a search for energy sources and sudden access to dystopian mirrors of their familiar fictional universes - to explicitly explore the nature of politics, defined both as the formal arrangement of public institutions and in Kate Millett's terms as 'power-structured relationships, arrangements by which one group of persons are controlled by another' (Millett 2000: 23). 'Mirror, Mirror' and 'Inferno' mark the first uses for political commentary of the mirror or parallel universe in popular television. The few earlier examples of the phenomenon - The Twilight Zone's (1959-64) 'Parallel' (1963), Star Trek's 'The Alternative Factor' (1967) and Lost in Space's (1965-8) 'The Anti-Matter Man' (1967, broadcast after Star Trek 
in the US but before Doctor Who in the UK) - are melodramas with little or no political content. ${ }^{1}$

The multiverse theory was first propounded as a philosophical device by Gottfried Leibniz and as a scientific possibility by Hugh Everett in 1957, without being taken up even by physicists until the 1970s (Wallace 2010: 54-6). The parallel world - a physical (or, sometimes, psychological or spiritual) place usually inaccessible to us - has older roots in myth, religion and folklore, and returned as a device in portal fantasy in the late 19th century. Within genre science fiction, alternate histories - worlds which begin similarly to ours, but which have somehow developed differently - developed from counterfactual historical flights of fantasy. Many of these are political satires, and the form itself may be seen as intrinsically political. 'All comparisons of an alternative history with actual history involve weighing in a moral balance, and all accounts of history changing and history protection require some moral justification for the attempted destruction or defence of a particular alternative history' (Stableford 2006: 19). In mainstream popular culture, the alternative universe is usually a close alternate to our own and, as Stableford identifies, is often politically inspired examples include An Englishman's Castle (1978) and SS-GB (2017). More specifically, though, and at the risk of developing an unsustainable topology of fictional multiverses, the worlds we are examining in Doctor Who and Star Trek are alternates to universes which are already fictional. This is only really possible with well-established, long running series where the primary fictional universe has developed consistent and familiar characteristics, and is a symptom of the density of modern 'transmedia' story-telling, and its immersive qualities (Thon 2015). Whereas parallels to the real world are generally authentic alternate histories, the counterparts of fictional worlds - as with 'Mirror, Mirror' and 'Inferno' - are often mirror universes, ones in which the familiar and the different are embodied within the same elements. They are inversions of the established fictional world, and it is the narratorial act of inversion - the specific elements which are inverted and how this is achieved - which allow them to function as ideological critiques. The mirror universe is an ideal vehicle for television shows to examine the ethos, morality and politics of human society, for the purpose either of propaganda or self-examination. 'Inferno' juxtaposes two universes in which a mad scientist brings about the end of the world, while 'Mirror, Mirror' contrasts the Federation's approach to negotiation and social structures to that of the Empire. By exploring the differences between these universes, we can identify a difference between the British and American political philosophies, and through the shows' abjection of particular modes of behaviour and society, their makers' prime political concerns.

\section{'Mirror, Mirror'}

The second season Star Trek episode 'Mirror, Mirror' is explicitly structured around a set of philosophical conundrums, both ontological and moral. The expansion of the Star Trek universe/franchise has led to further developments in the relationship between the prime and parallel universes, but here we will restrict our discussion to the episode from the original series. The title demands that we see the mirrored universes as a way to examine the 'prime' one of the Federation, perhaps in a rather self-congratulatory way given the visible and ideological evil of the Empire in the Other universe. Given the source of the title, however, the unspoken question - 'who is the fairest of them all?' - creates a space for an ambiguous interpretation, and it remains open to viewers to decide that the Federation is not as fair as it thinks it is. 
At the start of the show, before the opening credits, Kirk is negotiating with the Halkans - a pseudo-Hellenic pastoral people - who absolutely refuse to supply the Federation with dilithium crystal on pacifist grounds, even if it invites their genocide. Kirk counters their moral absolutism with ethical practice by presenting evidence of the Federation's peaceful history; the Halkans are unmoved, pointing out that societies change. We are presented with two immovable moral positions: a powerless pacifist civilization and a powerful one which nonetheless renounces force as a tool. While the Halkans are passive exemplars, the Federation's necessarily ambiguous position recognizes that coercion is sometimes required in pursuit of ethical aims, but Kirk's assertion that 'we won't' kill the Halkans to take the crystals invokes a Kantian morality of categorical moral imperatives (Kant 1993: 30). Star Trek's unspoken assumption is that while the Federation might occasionally be moved to violence, its motives are always for the best. While we never see the governmental system outside Starfleet, the audience is meant to assume that the Federation is a liberal, humanist government.

Following the inconclusive negotiations, the landing party beams up in the midst of an ion storm, and arrive on an Enterprise strangely changed. It transpires that Kirk, McCoy, Scotty and Uhura have been transported into a parallel universe, and are now aboard the ISS (Imperial Star Ship) Enterprise, part of the fleet of the Terran Empire. An insignia depicting a planet impaled on a dagger is prominently displayed throughout the ship and on the crew's uniforms, which are exoticised by medals, sashes, and jackboots. All crew carry stylized (but effective) daggers at their belts, invoking authority vested in personal violence, along with piracy, Orientalism and the extravagance of regimes invoking dread as a means of control. This polity is nakedly violent but apparently insecure, hence the overdetermined aesthetic reinforcement. The art displayed on board is also indicative of a culture different from the Federation: Spock has Romanesque military artefacts in his quarters, contrasting here with the Greek-style dress of the pacific Halkans. The most striking difference is in the personal grooming of senior crew: Kirk's jerkin reveals his muscular frame, while Uhura displays her midriff and sports thigh-high boots. Spock in the parallel universe has a goatee (subsequently termed 'Beard of Evil' in fandom and adopted as a marker in parodic mirror universes [TV Tropes]), which allows evil Kirk to utter the timeless phrase 'Has the whole galaxy gone crazy? Where's your beard?' to the Federation's Spock. Although virtually the whole episode is set on the ISS Enterprise, that ship's landing party has of course been translated to the USS Enterprise; the costumes in general, but the facial hair in particular, function as continual signifiers for potentially confused viewers about whom they are seeing in any particular scene.

Most crew members of the ISS Enterprise carry a device called an agonizer: in the first scene on the parallel ship Spock uses one on the transporter operator for his supposed inefficiency. Certain essential qualities about the Empire are gleaned from this event. The first is that each agonizer is for use on and not by its wearer: Spock demands that the terrified crew member hands over the device. That each person carries the means to cause himself pain signifies assent (though not necessarily agreement) to a social system predicated on retribution. Secondly, the agonizer is not used for moral correction: Spock uses it to improve efficiency in a cold and logical fashion. It is literally a 'technology of power', used 'to determine the conduct of individuals and submit them to certain ends or domination, an objectivization of the subject' (Foucault 1988a: 18). The agonizer symbolizes the Empire's construction of the subject simply as an operative rather than as a being in the humanist sense. Extended and highly public punishment is also inflicted for greater offences in 'agony booths': Chekhov is tortured in one after a failed attempt on Kirk's life. In the Empire's hierarchy, promotion is 
achieved through assassination but failure attracts exemplary retribution. This theatrical spectacle resembles one of those identified by Foucault as the exercise of 'sovereign power' in which the punishment's purpose demonstrates imbalance and excess rather than judicial measure; in this liturgy of punishment, there must be an emphatic affirmation of power (Foucault 1995: 48-9). That the Empire not only tolerates but actively encourages murderous competition demonstrates that it is a pragmatic rather than a moral system. Political power is vested in brute force and personal charisma, within the limits of an efficient and imperialist administration.

The pivotal figure in the episode is Spock, who unlike the human characters retains his familiar logical personality. In the Federation, his logic often appals emotional moralists such as Dr McCoy, but it usually coincides with the Federation's principles. On the Imperial ship, Spock thrives because logic is not incompatible with utilitarian amorality: wiping out the Halkans to get at the dilithium is simply efficient. This Spock, it is revealed, has profited from the multiple atrocities committed by the Empire's Kirk, and has cut a deal allowing him to pursue his scientific interests on the side. Spock has been ordered to kill Kirk if he does not wipe out the Halkans. The Federation's Kirk must persuade the Empire's Spock to save the Halkans and his comrades: he does so in a set-piece rhetorical appeal which attempts to demonstrate that logic is by its nature also moral. Spock believes that 'terror must be maintained or the Empire is doomed', which is, he says 'the logic of history'. Kirk's response is not, as might be expected, on moral grounds. Instead, he counters with the argument that Empires based on force are always unstable: the viewer is expected to conclude that liberal democracy is a logical choice and pragmatic politics. Thus 'Mirror, Mirror' demonstrates Foucault's assertion that regimes of tolerance are tolerant not for Kantian reasons of categorical imperatives, but because a state's prime interest is only ever its own survival (During 1992: 150).

Kirk's argument for the superior efficiency of a humanist social structure is demonstrated by the parallel events on board the USS Enterprise where the Imperial landing party are immediately identified as interlopers and confined to the brig, with Spock informing evil Kirk, 'Your authority on this ship is extremely limited, Captain'. While Spock acknowledges Kirk's rank, it does not confer legitimacy on a man who relies on threats and bribes. Power in the Federation operates within legally constituted bounds, rather than its charismatic and criminal exercise within the Empire. However, in some senses, the brutal Empire is perhaps less pervasively oppressive than the Federation. Modern power of the kind exercised in the Federation is invisible, self-imposed and thus harder to resist because it feels - to the subject generated by it - like freedom. The Federation's liberal tolerance requires acculturated citizens who internalize its values and constantly examine themselves for compliance. The Captain's Log in Star Trek is more than an expository device and a means of answering to authority - it requires the Captain to conduct the kind of self-analysis Foucault discusses: 'the soul will be able to discover rules to serve as a basis for just behaviour and political action. The effort of the soul to know itself is the principle on which just political action can be founded' (Foucault 1988a: 28). It is this self-examination which renders the Federation an ethical polity: if its operatives simply behaved according to categorical imperatives they would be moral subjects in the Kantian sense but not ethical subjects, lacking the need to search for an ethos of practice (During 1992: 180). Traversing the galaxy with only a fuzzy grasp of the Prime Directive of non-interference, the crew of the USS Enterprise have to develop an ethos in response to specific situations much as, according to Foucault, the Stoics did: the subject is formed in the process of reflecting on what was done each day and what will be done, rather than on comparing the soul to some ideal condition (Foucault 1988a: 35). 
Conversely, the Empire is supremely uninterested in philosophy, morality and its operatives' beliefs and feelings. While the Federation seems to want its crews to identify with its liberal ideology - as Foucault notes, 'this technology of self-examination...is much more concerned with thought than with action'(Foucault 1988a: 45) - the Empire demands only compliance. This indifference seems efficient in its disregard for moral imperatives and legal niceties, but its blindness to subjective interiority limits its ability to respond to challenges. The Empire's failure to acculturate rather than simply dominate its subjects may prove to be a fatal flaw if, as is suggested, Spock does indeed accept Kirk's argument that a social order must be a moral one. Given the audience's assumed agreement with Kirk's rhetorical position and its humanist politics, the episode seems to end optimistically with the inevitable reform of the Empire and its 'return' to normative historical determinants. However, Spock's noncommittal response to Kirk's proposal that he take power and transform the Empire - 'I shall consider it' - replaces inevitability with contingency, and refuses to validate our assumptions of political superiority. An even more serious challenge to Star Trek's historical projection of liberal values is in the episode's other lacuna, the unresolved question of how the Federation's Starfleet acquires the dilithium without committing genocide against the Halkans. The opening of 'Mirror, Mirror' seemed to position this moral deadlock as the episode's narrative and philosophical driver and its satisfactory conclusion as the triumph of liberal values. However, the dramatic distraction of confronting the Empire's absolute and unquestionable evil allows Star Trek to evade solving the Federation's own moral conundrum. This evasion indicates that Star Trek is clearer about which political actions are immoral than what constitutes a moral or principled exercise of power. In the absence of a practical solution to the Federation/Halkan stand-off, we can only rely on a general sense of good moral intentions informed by a numinous categorical imperative. Perhaps, after all, the lesson is not the specific ideological positions compared in the episode - in which the comparison seems to be between the liberal Federation and the rapacious Empire - but that the moral principles underlying Star Trek's liberal doctrine evaporate in extremis.

\section{'Inferno'}

While Star Trek assumes a comprehensive morality underpinning its society, Doctor Who generally takes a more oblique, pragmatic, and messy approach to immediate political and social pressures. In 'Inferno', the Doctor is privately experimenting at a research site, guarded by UNIT (United Nations Intelligence Taskforce), devoted to drilling through the earth's crust in search of new energy sources. Despite his advice, and that of Sutton, an independent and autonomous Australian expert, the lead scientist Dr Stahlman (= Steel Man) refuses to slow the project down even as personnel are killed or turned into monsters called Primords. When the computer demonstrates that the project is endangering the planet, Stahlman sabotages it and attempts to thwart appeals to 'the Minister' by the resident civil servant Sir Keith Gold. In essence, the plot is familiar: a mad scientist loses all sense of rationality, rejecting others' expertise and the lawful restraint of bureaucratic government to advance his own crazed plans.

The Doctor's role in this scenario is dual: in contrast to Stahlman he provides independent advice which merges morality and reason to scientists, military operatives and civil servants (in a sense he is a charismatic version of the computer). Narratively, his experiments with the Tardis transport him into a parallel fascistic universe, establishing a similar dramatic and philosophical problem as explored in 'Mirror, Mirror'. Here too the drilling project threatens 
to destroy the planet. On arrival in the parallel universe the Doctor notices that the workshop is much neater and adorned by pictures of a Leader with the slogan 'Unity is Strength'. As in 'Mirror, Mirror', this universe is peopled with differentiated versions of regular characters. Brigade Leader (not Brigadier) Lethbridge-Stewart has lost his moustache and gained both an eyepatch and facial scar. Most characters are wearing paramilitary apparel with Republican Security Force badges rather than formal military uniforms, have titles including the word Leader, and operate within a Nazi-like structure in which law, party and personal authority are merged. The RSF is a Gestapo which relies on the Defence of the Republic Act 1943 to legitimize summary execution, and Britain is a bureaucratic-totalitarian state. Professor Stahlman is now Director Stahlmann - the second 'n' reinforces the episode's tendency to look to Nazi Germany for its opposites - and despite the protests of the Doctor and Sutton (here a non-Party advisor) Stahlmann ultimately causes the destruction of the planet.

While power in the prime world is distributed between scientists, advisors and civil servants, leading to friction but eventually to a successful resolution, in the dystopian Britain the concentration of authority in militaristic and personal hierarchies leaves no space for problem-solving and negotiation. In both universes Stahlman/n behaves dictatorially, but only in the mirror can he ultimately succeed. In the prime world, disruptive elements such as the Doctor and Sutton have both the charismatic and scientific authority required to persuade others to reassess their positions. Despite its pettifogging bureaucracy and institutional tensions, the prime world of UNIT and the research station is capable of using these qualities positively: whether or not the state's concern is its own maintenance or that of its citizens, it practices 'political arithmetic', the acquisition of knowledge, practices and competencies'(Foucault 1988b: 147). In Republican Britain, unruly elements are eliminated; the 'Scientific Labour Camp' and its polis lacks both energy and arithmetic. There is no way to disrupt the hierarchies and practices of the Party-Scientific-Military unified edifice sufficiently to save the world.

The deficiencies of the Republic are primarily structural. Reason, science and negotiation are subject to charismatic authority tied into a social hierarchy which relies on faux-legality, symbolized by the Defence of the Republic Act (echoing the real world's Defence of the Realm Act). The Republic abjects transgression and disruption, but the RSF's performance of due process masks inherent cruelty and piratical behaviour, such as the Director's probable murder of Sir Keith Gold. Despite being produced in the midst of the Cold War and adopting elements of iconography from Orwellian anti-Communism, the political Other in 'Inferno' is historic Nazism rather than the contemporary geopolitical enemy. This is signified by the Republic's militarization ('oafs in uniform' are running the place, the Doctor observes), Gestapo aesthetics and its administrative legalism which the Doctor highlights when he calls Lethbridge-Stewart a 'Proper little bureaucrat' who 'can't shoot me unless you've filled in all the forms'. As Layton notes, the show's promotion of arguments, negotiations and dialogue demonstrates that 'democracy is not the opposite and antidote to communism, but the opposite and antidote to totalitarianism' (Layton 2012: 297). As such, the Republic's ills are those held by Doctor Who's creators to be most unwelcome - but potentially present in both the familiar 'Whoniverse' and that of the viewers. Post-war British popular culture reproduces a low-level impatience with and suspicion of bureaucracy, evident in films such as Passport to Pimlico (Cornelius, 1949) and The Happy Family (Box, 1952), and television series including The Fall and Rise of Reginald Perrin (1976-9) and Yes Minister (1980-4). The Doctor's antagonism towards officialdom derives from his insistence on the primacy of science and reason against either contingent politics or officious red-tape - Layton asserts that he 'must always have an antagonistic relationship with bureaucracy' (Layton 2012: 255) 
- and in this he echoes his science fictional predecessor, Quatermass (particularly in Quatermass II, 1955). All of these, though, echo Doctor Who's understanding that bureaucracy within a democratic system is essentially benign even if it is often frustrating: Sir Keith's very belated acceptance of the need to stop drilling in the prime universe is not merely for dramatic effect but indicative of the system's creaking ability to deal with pressing threats. Experts, civil servants, military security and computers represent a Wilsonian vision of technocratic progress within a political system of diffused and flexible power: threats to the system - here metaphorically represented as the possible end of the world - should be defused through appeals to reason and the rightful but consultative application of democratic authority.

In contrast, the characteristic representatives of the fascist state we encounter are markedly inflexible and unimaginative - the contrarian Sutton interestingly refers to them as 'zombies'. Elizabeth Shaw, who as Liz Shaw in the prime world is a civilian scientist and the Doctor's assistant, is now a paramilitary officer. The Doctor ascertains that she had once considered becoming a scientist but instead joined the RSF. She is open to reason and eventually aids the Doctor's escape. Brigade Leader Lethbridge-Stewart is more representative of the RSF: even as the Party abandons him, he cannot make the moral and imaginative leap Shaw does, but instead plots to dupe the Doctor, then panics when that fails. In a rigid and hierarchical political structure, the acculturated population cannot adapt to new realities. Control and surveillance are all: the Brigade Leader and Section Leader Shaw are most disturbed by the Doctor's absence from all records, which have 'never' been wrong before. Their shock echoes Foucault's description of the modern subject being a creation of knowledge, in which state supervision by institutions such as the police, health services and education turns individuals and their behaviours into cases (Foucault 1988a).

Pertwee-era Doctor Who's repeated use of the energy and mad scientist tropes - like its exact contemporary BBC series Doomwatch (1970-2) - indicates that rather than partaking in Cold War paranoia, it is more concerned with unchecked technocracy and environmental doom. Despite these popular anxieties, on the whole Doctor Who is optimistically liberal. As Layton observes, 'Who is a product of Enlightenment values: 'pro-democracy' but much more antiauthoritarian' (Layton 2012: 296). It condemns - through destroying the mirror universe inflexibly hierarchical and authoritarian politics and power relations. The Republic cannot survive because it represses imagination and autonomy, rejects science and reason in favour of status, and produces subjects largely incapable of developing their potentials or of reacting nimbly to threats. It is a totalizing system in which state knowledge of everything and everyone has paralysed it and closed it off to understanding the fluidity of identities and conditions. Chapman asserts that the Doctor's expository monologue about the mirror universes proving the existence of 'free will' is evidence of 'an idea of history that allows for the role of individual agency rather than an entirely deterministic or structural explanation in which events are brought about by impersonal forces outside people's control' (Chapman 2013: 87). Layton believes that the underpinning liberal political philosophy of 'Inferno' is a theory of rights, yet a poststructural analysis suggests further that the prime universe survives because power as it is practiced is distributed amongst institutions and outside them, rather than formally invested in the language of rights (Layton 2012: 298): the military is not in charge; outsiders are eventually respected for their skills; the civil service may be slow but it provides checks and balances; the Doctor's impartiality as well as that of the computer are appreciated (eventually). The seeds of the Republic are present in Stahlman's distortion of truth and the Brigadier's stiff by-the-book approach (the Doctor teases him by saying that 'There are times when you strongly remind me of your other self') but the final resolution 
makes it clear that the society 'we' have is superior because it is tolerant and flexible, though this is of course a source of suspicion for Foucault, for whom liberal tolerance is simply an extension of invisible power. 'Inferno' in this light is - as Fiske called it - capitalist propaganda (Fiske 2004: 99) because while the Republic's faults are visible in its response to catastrophe and its explicit tyranny, the prime world's political principles are off-screen and assumed to be relatively benign, although James Chapman describes its near-future setting as neo-dystopian: paranoid, vulnerable and strewn with restricted sites and military installations (Chapman 2013: 82).

\section{Conclusion}

The Federation and Doctor Who's juridical contexts are both optimistic: laws and political structures exist to provide the operating system for an assumption that individuals have fundamental rights and humans are essentially good: appeals to reason and the distribution of power observed in 'Inferno' only work because the majority of the individuals in society have a sense of fairness that outweighs self-interest. The Republic assumes that its citizens must be brutalized into obedience, hence the scientists' desertion at the moment of crisis. The Empire, too, is a Hobbesian nightmare in which crews are either bribed or tortured into compliance. Both the Republic and the Empire behave towards its citizens like the states described by Foucault:

Since the state is its own finality...it is clear that the governments ... worry about individuals...only insofar as they are somehow relevant for the reinforcement of the state's strength: what they do their life, their death, their activity, their individual behavior, their work...the individual becomes pertinent for the state insofar as he can do something for the strength of the state (Foucault 1988b: 152).

In Star Trek's evil twin universe, power is devolved onto the individual but exists in a moral vacuum of utilitarianism. The Federation's - and the show's - solution is not Doctor Who's messy distribution of competing types of authority in rough balance, but a system of powerrelationships which require governmentality (reflection on the gap between one's actions and the rules of conduct) and self-fashioning (Foucault 1988a). The Kantian categorical moral imperative of the Federation is assumed, and the responsible individual is expected to develop a politics through internalizing these values and demonstrating their superiority through praxis. It is a regime of liberal tolerance which, unlike the Empire's brutal pragmatism, maintains and extends its power by requiring its citizens to become public, selfreflective ethical practitioners. It is the Kirk who has been fashioned under these conditions who can confidently tell the Empire's Spock that a single individual can change the world. In Doctor Who we are presented with two worlds, one of which uses a perverted form of legal process to justify authoritarian politics, and is doomed as a result. 'Our' world, represented if somewhat problematically - by the prime-Whoniverse contains the potential for such a polity, but its solution is a pragmatic, benign and flexible state in which power is diffused and non-hierarchical. Heroic individuals can identify solutions, but cannot succeed without reciprocity from others who can act within social structures: the Doctor cannot save the world on his own.

Ultimately, viewers of Star Trek and Doctor Who are left to rely on the benevolence of the fictional polities and, by extension, their real world government. The Empire and the Republic need not worry us: their anti-life qualities doom them to destruction - physical in 
the case of 'Inferno' and political in 'Mirror, Mirror'. But if we follow Foucault, we should worry about the Doctor's Britain and the Federation because their encouragement of 'bourgeois' individuation correlates with a totalizing tendency. The checks and balances of law, order, expertise, sexuality and democracy which triumph in 'Inferno' resist even tolerant totality, but Star Trek's general silence on the lives led by civilians outside Starfleet's structures is more disquieting.

In both texts the dystopian society, rather than being an inversion of the primary fictional universe, is actually the viewers' reality seen through a distorting mirror. They are reductiones ad absurdum of prevailing cultural and political systems, and therefore reveal contemporary social anxieties and conflicts. Star Trek's dystopia melds utilitarian selfinterest and imperialism; in Doctor Who the nightmare scenario is all-encompassing bureaucracy which enables totalitarianism. Neither show, despite appearing in the midst of the Cold War, chose as their dystopian reflection the contemporary adversary of Soviet Communism. Instead, we would claim, both look to their historical enemies for their 'others'. While never actually encountering Nazi Germany in the 'classic' series, Doctor Who has consistently turned to the Third Reich for its models of dehumanised evil, most notably through the Daleks (DiPaulo 2010: 968), but also the Cybermen (Geraghty 2008: 95) and, more recently, a post-apocalypse British state in 'Turn Left' (Charles 2009: 23). The Empire in 'Mirror, Mirror' is iconographically classicist and oriental, but its piratical practices echo the buccaneering early modern British Empire from which the thirteen colonies seceded, and which America's foundation on explicit legal and philosophical principles implicitly condemns. In 'Inferno', the political problem can only be resolved by apocalypse; in 'Mirror, Mirror' the evil empire is potentially redeemable given the historical precedent of enlightenment America's emergence from its colonial origins.

Star Trek generally reflects a sense of optimism, more common in US science fiction than elsewhere (Aldiss with Wingrove 1986: 175-7). In 'Mirror, Mirror' we are reminded, by the existence of the evil Empire, of the benign utopianism which the Federation - and by extension, the United States as a 'shining city on a hill' - represents. Although both programmes are set in the viewers' future, any suggestion in Star Trek that the Empire is a potentiality is muted; in Doctor Who, however, in the midst of the febrile political environment that was the legacy of the progressive 1960s as it became the disillusioned and anxious 1970s, the warnings of statist power and its disastrous implications are more stark. Both Doctor Who and Star Trek, it can be shown, are products of their and our political conditions; but do they have influence in forming or reforming those environments? While television generally is agreed to have powerful, if diverse and diffuse, ideological effects (Hood 1980), it might be held that long running and familiar popular programmes have a more direct role to play in acculturating audiences in a similar way to that in which the shows' regular characters are apparently acculturated. The Doctor's realization in 'Inferno' that 'not everything runs parallel ... an infinity of universes, ergo an infinite number of choices ... so free will is not an illusion after all ... the pattern can be changed' is the serial's message for the audience at home, both philosophical and political. In this it seems to accord with Kirk's admonition to Spock. Though deriving from different political histories, as we have shown, both call for a liberal praxis. In 'Inferno', the consequence of illiberality is total destruction - a fairly unambiguous warning, which provides both ideological and narrative closure. 'Mirror, Mirror', however, which ends without solving the Halkan pacifist enigma, cannot fulfill its liberal agenda, and lapses into silence. While Doctor Who provides a dystopian reflection, Star Trek, more ambitiously, also offers a principled utopia within an ethically compromised universe, albeit one whose paradoxes it does not ultimately solve. 


\section{References}

Aldiss, Brian W. with Wingrove, David (1986), Trillion Year Spree: The History of Science Fiction, London: Victor Gollancz.

Anon (1970), Radio Times, 2431, 11 June.

Box, Muriel (1952), The Happy Family, London: London Independent Producers.

Chapman, James (2013), Inside the Tardis: The Worlds of Doctor Who: A Cultural History, London: IB Tauris.

Charles, Alec (2008), 'War without End?: Utopia, the Family, and the Post-9/11 World in Russell T. Davies's Doctor Who', Science Fiction Studies, 35:3, November, pp. 450-465.

Charles, Alec (2009), 'The Flight from History: From H. G. Wells to Doctor Who - and Back Again', Colloquy: Text Theory Critique, 17, pp. 16-33.

Cornelius, Henry (1949), Passport to Pimlico, London: Ealing.

Dipaolo, Marc Edward (2010), 'Political Satire and British-American Relations in Five Decades of Doctor Who', The Journal of Popular Culture, 43:5, pp. 964-987.

During, Simon (1992), Foucault and Literature, London: Routledge.

Fiske, John (2004), 'Popularity and ideology: a structuralist reading of Doctor Who', in Leah R. Vande Berg, Lawrence A. Wenner and Bruce E. Gronbeck (eds), Critical Approaches to Television, 2nd edition, Boston and New York: Houghton Mifflin Company, pp. 86-109.

Franklin, H. Bruce (2000), Vietnam and Other American Fantasies, Amherst, MA:

University of Massachusetts Press.

Foucault, Michel (1988a), 'Technologies of the Self' in Luther H. Martin, Huck Gutman and Patrick H. Hutton (eds), Technologies of the Self: A Seminar with Michel Foucault, London: University of Massachusetts Press, pp. 16-49.

Foucault, Michel (1988b), 'The Political Technology of Individuals' in Luther H. Martin, Huck Gutman and Patrick H. Hutton (eds), Technologies of the Self: A Seminar with Michel Foucault, London: University of Massachusetts Press, pp. 145-162.

Foucault, Michel (1995), Discipline and Punish: The Birth of the Prison (trans. Alan Sheridan), New York: Vintage.

Fulton, Roger (2000), Encyclopedia of TV Science Fiction, London: Boxtree

Geraghty, Lincoln (2007), Living with Star Trek: American Culture and the Star Trek Universe, London: I. B. Tauris. 
Geraghty, Lincoln (2008), 'From Balaclavas to Jumpsuits: The Multiple Histories and Identities of Doctor Who's Cybermen', Atlantis: Journal of the Association of AngloAmerican Studies, 30:1, June, pp. 85-100.

Hassler, Donald M. and Wilcox, Clyde (1997), 'Introduction' in Hassler and Wilcox (eds), Political Science Fiction, Columbia: University of South Carolina Press, pp. 1-6.

Hills, Matt (2010), 'Doctor Who' in David Lavery (ed.), The Essential Cult TV Reader, Lexington, Kentucky: University Press of Kentucky, pp. 97-103.

Hood, Stuart (1980), On Television, London: Pluto Press.

Howe, David J. and Walker, Stephen James (1998), Doctor Who: The Television Companion, London: BBC.

Hruschak, Ted Michael and Meyers, Richard (1979), 'Lost in Space: Complete Episode Guide', Starlog, 21, April, pp. 37-43.

Jenkins, Henry and Tulloch, John (1995), 'Beyond the Star Trek Phenomenon: Reconceptualizing the Science Fiction Audience', in John Tulloch and Henry Jenkins , Science Fiction Audiences: Watching Doctor Who and Star Trek, London: Routledge, pp. 324.

Kant, Immanuel (1993), Grounding for the Metaphysics of Morals (ed. and trans. James W. Ellington), Cambridge, MA: Hackett.

Layton, David (2012), The Humanism of Doctor Who, Jefferson, NC: McFarland.

Millett, Kate (2000), Sexual Politics, Chicago: University of Illinois Press.

O'Day, Andrew (2010), 'Towards a Definition of Satire in Doctor Who', in Christopher J. Hansen (ed.), Rumination, Peregrinations and Regenerations: A Critical Approach to Doctor Who, Newcastle Upon Tyne: Cambridge Scholars Publishing, pp. 264-282.

Orthia, Lindy A. (2011), "Paradise is a little too green for me": Discourses of environmental disaster in Doctor Who 1963-2010', Colloquy: text theory critique, 21, November, pp. 21-45.

Reagin, Nancy R. (2013), 'Introduction: Time Warps and Future Histories', in Nancy R. Reagin (ed.), Star Trek and History, Hoboken, New Jersey: John Wiley \& Sons, pp. 1-3.

Stableford, Brian (2006), Science Fact and Science Fiction: An Encyclopedia, New York and London: Routledge.

Thon, Jan-Noël (2015), 'Converging Worlds: From Transmedial Storyworlds to Transmedial Universes', StoryWorlds: A Journal of Narrative Studies, 7: 2, Winter, pp. 21-53.

Tulloch, John and Alvarado, Manuel (1983), Doctor Who: The Unfolding Text, London: Macmillan. 
TVTiP (nd), http://bufvc.ac.uk/tvandradio/tvtip/index.php/prog/115698. Accessed 22 June 2016.

TV Tropes (nd), 'Beard of Evil', http://tvtropes.org/pmwiki/pmwiki.php/Main/BeardOfEvil. Accessed 22 June 2016.

Wallace, David (2010), 'Decoherence and Ontology (or: How I learned to stop worrying and love FAPP); in Simon Saunders, Jonathan Barrett, Adrian Kent and David Wallace (eds), Many Worlds? Everett, Quantum Theory, and Reality, Oxford: Oxford University Press, pp. 53-72.

Whitfield, Stephen E. (1968), The Making of Star Trek, New York: Ballantine Books.

Williams, Raymond (1974), Television: Technology and Cultural Form, London: Fontana/Collins.

Zicree, Marc Scott (1982), The Twilight Zone Companion, New York: Bantam.

\section{Television programmes}

Doctor Who (1963-89, 2005-present, United Kingdom: BBC). 'Inferno' (9 May-20 June 1970).

Doomwatch (1970-2, United Kingdom: BBC).

Englishman's Castle, An (1978, United Kingdom: BBC).

Fall and Rise of Reginald Perrin, The (1976-9, United Kingdom: BBC).

Lost in Space (1965-8, United States: CBS). ‘The Anti-Matter Man’ (27 December 1967).

Quatermass II (1955, United Kingdom: BBC).

SS-GB (2017, United Kingdom: BBC).

Star Trek (1966-9, United States: NBC). 'The Alternative Man' (30 March 1967).

Star Trek (1966-9, United States: NBC). 'Mirror, Mirror' (6 October 1967).

Twilight Zone, The (1959-64, United States: CBS). 'Parallel' (14 March 1963).

Yes Minister (1980-4, United Kingdom: BBC). 


\footnotetext{
1 'Inferno' was originally broadcast on BBC1 on 9 May-20 June 1970 (Howe and Walker 1998: 192-3). 'Mirror, Mirror' was originally broadcast on NBC on 6 October 1967 (Whitfield 1968: 410), and first broadcast in the United Kingdom on BBC1 on 15 June 1970 (Anon 1970: 35). 'Parallel' was originally broadcast on CBS on 14 March 1963 (Zicree 1982: 349). 'The Alternative Factor' was originally broadcast on NBC on 30 March 1967 (Whitfield 1968: 409). 'The Anti-Matter Man' was originally broadcast on CBS on 27 December 1967 (Hruschak and Meyers 1979: 42), and first broadcast on Thames TV in London on 16 March 1970 (TVTiP), but in late 1969 in some other UK ITV regions (Fulton 2000: 327-8).
} 